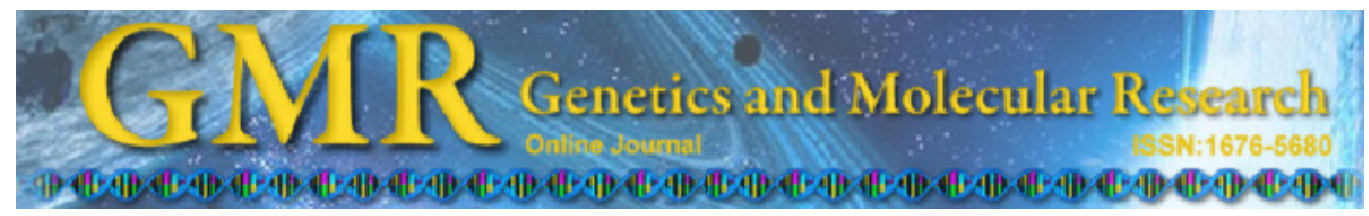

$\underline{\text { Short Communication }}$

\title{
Development and characterization of microsatellite primers in Pogostemon cablin (Lamiaceae)
}

\author{
S.S. Sandes ${ }^{1}$, J.B. Pinheiro ${ }^{2}$, M.I. Zucchi ${ }^{3}$, M. Monteiro ${ }^{3}$, \\ M.F. Arrigoni-Blank ${ }^{1}$ and A.F. Blank ${ }^{1}$ \\ ${ }^{1}$ Laboratório de Cultura de Tecidos e Melhoramento Vegetal, \\ Departamento de Engenharia Agronômica, Universidade Federal de Sergipe, \\ São Cristóvão, SE, Brasil \\ ${ }^{2}$ Laboratório de Diversidade Genética e Melhoramento, \\ Departamento de Genética e Melhoramento de Plantas, \\ Escola Superior de Agricultura "Luiz de Queiroz", Universidade de São Paulo, \\ Piracicaba, SP, Brasil \\ ${ }^{3}$ Laboratório de Biologia Molecular, \\ Agência Paulista de Tecnologia dos Agronegócios, Polo Centro Sul, \\ Piracicaba, SP, Brasil \\ Corresponding author: A.F. Blank \\ E-mail: afblank@ufs.br
}

Genet. Mol. Res. 12 (3): 2837-2840 (2013)

Received January 30, 2013

Accepted July 5, 2013

Published August 8, 2013

DOI http://dx.doi.org/10.4238/2013.August.8.4

\begin{abstract}
Microsatellite primers were developed and optimized for patchouli (Pogostemon cablin) to characterize the patchouli Active Germplasm Bank of Universidade Federal de Sergipe. Creation of a genomic library for patchouli enabled the design of 12 microsatellite primers. Six of these microsatellites were polymorphic, revealing two well-defined groups of individuals that possess exclusive alleles. The data allowed us to characterize the patchouli active Germplasm Bank, identify its genetic diversity, and provide new information for researching this species.
\end{abstract}

Key words: Genetic diversity; Lamiaceae; Pogostemon cablin; SSR 


\section{INTRODUCTION}

Patchouli [Pogostemon cablin (Blanco) Benth.] is an aromatic, herbaceous plant that belongs to the Lamiaceae family, and is native to Southeast Asia. Its leaves produce an essential oil that is highly regarded in the perfume and cosmetic industries (Swamy et al., 2010). Because of the importance of patchouli essential oil, research groups around the world studied the production of sesquiterpenes that compose the oil in order to create more profitable and higher quality products (Paul et al., 2010).

A patchouli collection from Universidade Federal de Sergipe (UFS) has been chemically and morpho-agronomically characterized (Blank et al., 2011). However, for complete characterization of a germplasm bank, molecular markers are an efficient alternative. Microsatellite markers, or simple sequence repeats (SSR), are used for a variety of applications in plant genetics and breeding because they are reproducible, multi-allelic, codominant, relatively abundant, and have good genomic coverage (Remya et al., 2010). However, because SSR primers have not yet been found in species closely related to patchouli, it was necessary to construct a genomic library and design oligonucleotide initiators. In this study, we constructed an enriched genomic library and designed microsatellite primers for patchouli.

\section{MATERIAL AND METHODS}

Young leaves of the patchouli accessions of the Active Germplasm Bank of the UFS were collected. There are 10 genotypes in the Active Germplasm Bank, and efforts are being made to collect a larger number of divergent materials all over the world (Table S1). The plant material was stored in liquid nitrogen for lyophilization. After lyophilization, the plant material was ground, and the resulting powder was used for the subsequent steps. The CTAB protocol, described by Doyle and Doyle (1990), was used to extract the genomic DNA. DNA was quantified on $1 \%$ agarose gel stained with SYBR safe, using lambda phage DNA at different concentrations.

A microsatellite-enriched library was obtained using adapted protocols from Billotte et al. (1999), with modifications. Genomic DNA from one genotype of patchouli was digested with $A f a$ (Invitrogen), and enriched in microsatellite fragments using $(\mathrm{CT})_{8}$ and $(\mathrm{GT})_{8}$ motifs. Microsatellite-enriched DNA fragments were ligated into pGEM-T Easy Vector (Promega, Madison, WI, USA) and were used to transform Epicurian Coli XL1-Blue Escherichia coli competent cells (Promega). The positive clones were selected using the $\beta$-galactosidase gene and then were grown overnight with ampicillin. Sequencing reactions $(10 \mu \mathrm{L})$ contained 200 ng plasmid DNA, 0.5 pmol SP6 primer, $0.4 \mu \mathrm{L}$ BigDye Terminator mix (version 3.1; Applied Biosystems, Foster City, CA, USA), $1 \mathrm{mM} \mathrm{MgCl}$, and $40 \mathrm{mM}$ Tris-HCl, $\mathrm{pH}$ 9.0. Sequencing reactions were performed in a thermal cycler (MJ Research, BioRad, Hercules, CA, USA) under the following conditions: 2 min at $96^{\circ} \mathrm{C}$ for the first denaturation, followed by 26 cycles of $45 \mathrm{~s}$ at $96^{\circ} \mathrm{C}, 30 \mathrm{~s}$ at $50^{\circ} \mathrm{C}$, and $4 \mathrm{~min}$ at $60^{\circ} \mathrm{C}$. Polymerase chain reaction (PCR) products were precipitated with isopropanol (65\%), centrifuged, and washed with $70 \%$ alcohol. Ninety-six positive clones were sequenced on an ABI 3700 automated sequencer (Applied Biosystems).

The WebSat software (http://wsmartins.net/websat/) was used to identify the microsatellite-containing regions using at least $12 \mathrm{bp}$. A total of 12 primer pairs were designed using the Primer3 software (http://frodo.wi.mit.edu/primer3/). The Gene Runner v. 3.05 (http:// www.generunner.net/) program was used to validate the parameter values that were estab- 
lished for primer design and showed the probability of secondary structure formation that prevented primer usage.

The amplification reaction used $3.0 \mu \mathrm{L} 5 \mathrm{ng} / \mu \mathrm{L}$ DNA, $0.5 \mu \mathrm{L} 10 \mu \mathrm{M}$ forward primer, $0.5 \mu \mathrm{L} 10 \mu \mathrm{M}$ reverse primer, $1.6 \mu \mathrm{L} 2.5 \mathrm{mM}$ dNTPs, $1.0 \mu \mathrm{L} 1 \mathrm{U} / \mu \mathrm{L}$ Taq DNA polymerase, $2.0 \mu \mathrm{L}$ 10X PCR buffer (50 mM KCl, $10 \mathrm{mM}$ Tris-HCl, $\mathrm{pH} 8.9), 0.8 \mu \mathrm{L} 25 \mathrm{mM} \mathrm{MgCl}_{2}$, and $10.6 \mu \mathrm{L} \mathrm{H} \mathrm{H}_{2} \mathrm{O}$. The amplification program consisted of a denaturation step at $94^{\circ} \mathrm{C}$ for $5 \mathrm{~min}$ followed by 33 amplification cycles $\left(94^{\circ} \mathrm{C}\right.$ for $1 \mathrm{~min}$, followed by the specific annealing temperature for each primer pair (Table 1), and $72^{\circ} \mathrm{C}$ for $1 \mathrm{~min}$ ), and a final elongation step at $72^{\circ} \mathrm{C}$ for $10 \mathrm{~min}$. To amplify the Pca3, Pca6, and Pca8 primer pairs, a touch-down thermal profile was used, which was similar to the program used above, except that the annealing temperature was initially reduced in steps of $2^{\circ} \mathrm{C}$ every 7 cycles, from $67^{\circ}$ to $55^{\circ} \mathrm{C}$, followed by 30 cycles at $53^{\circ} \mathrm{C}$. The PCR-amplified fragments were run on a $7 \%$ denaturing polyacrylamide electrophoresis gel and stained with silver nitrate (Creste et al., 2001).

\section{RESULTS AND DISCUSSION}

The 6 polymorphic microsatellite primers are shown in Table 1 . The primer Pcal had the most alleles (4), and all other loci had 2 alleles, resulting in an average of 2.33 alleles per polymorphic locus. Of the microsatellite loci that were polymorphic, 5 were composed of dinucleotide repeats, and only one had a trinucleotide repeat. The largest expected heterozygosity $\left(H_{\mathrm{E}}\right)$ for the locus Pcal was 0.678 . For the other loci (Pca3, Pca4, Pca6, Pca7, and Pca8), the $H_{\mathrm{E}}$ was 0.356 (Table 1). The $H_{\mathrm{E}}$ observed for all loci was less than the observed heterozygosity $\left(H_{\mathrm{O}}\right)$, indicating an excess of heterozygotes compared to expectations under Hardy-Weinberg equilibrium (HWE). The high $H_{\mathrm{O}}$ and $H_{\mathrm{E}}$ averages may be due, in part, to

\begin{tabular}{|c|c|c|c|c|c|c|c|c|}
\hline Locus & GenBank No. & Primer sequence (5'- 3') & Repeat motif & $\mathrm{Ta}\left({ }^{\circ} \mathrm{C}\right)$ & Size range $(b p)$ & $N_{\mathrm{A}}$ & $H_{\mathrm{O}}$ & $H_{\mathrm{E}}$ \\
\hline$\overline{P c a 2}$ & GF111966 & $\begin{array}{l}\text { F: GTCGAAGGTTCAGCCTCTTG } \\
\text { R: TCGGAACATCAGCAATGAG }\end{array}$ & $\operatorname{CAATG}_{(3)}$ & 58 & $125-130$ & 1 & 0.000 & 0.000 \\
\hline Pca5 & GF111967 & $\begin{array}{l}\text { F: CCCTTTACAATAACCTCGACA } \\
\text { R: ATCAACAGCACACCGTAGAGA }\end{array}$ & TATT $_{(3)}$ & 61 & $130-134$ & 1 & 0.000 & 0.000 \\
\hline Pcall & GF111968 & $\begin{array}{l}\text { F: TTCCCCTTAGATTGTGCAAA } \\
\text { R: AGACAAAGTGAGGCATCTGATT }\end{array}$ & $\mathrm{TTGA}_{(3)}$ & 61 & $232-238$ & 1 & 0.000 & 0.000 \\
\hline Pcal2 & GF111969 & $\begin{array}{l}\text { F: AAAAAGCTCACGCCCTTCT } \\
\text { R: CTCGTTATCAATGGGATCAGG }\end{array}$ & $\mathrm{AACC}_{(3)}$ & 65 & $250-254$ & 1 & 0.000 & 0.000 \\
\hline Pcal & GF111970 & $\begin{array}{l}\text { F: ACACACTCCCCCACCATAC } \\
\text { R: CCACCTGTTTCTTTCACTTCC }\end{array}$ & $\mathrm{GA}_{(16)}$ & 57 & $228-240$ & 4 & 0.167 & 0.678 \\
\hline Pсa3 & GF111971 & $\begin{array}{l}\text { F: CCATTTCGTCACCTCTC } \\
\text { R: AAACAGGCAAGTGAAAGT }\end{array}$ & $\mathrm{CA}_{(8)}$ & 53 & 164-168 & 2 & 0.167 & 0.356 \\
\hline Pca4 & GF111972 & $\begin{array}{l}\text { F: AGGGAAGCAGGGAAAACATT } \\
\text { R: CTTGCGGCATTTAGGGATAC }\end{array}$ & $\mathrm{AG}_{(14)}$ & 65 & $258-266$ & 2 & 0.167 & 0.356 \\
\hline Pca6 & GF111973 & $\begin{array}{l}\text { F: ACAAAGGGTTGACGATTG } \\
\text { R: GTGATGAAACTGTCTCTCCTG }\end{array}$ & $\begin{array}{l}\mathrm{TG}_{(4)} \cdot \mathrm{TC}^{-T G} \mathrm{~T}_{(5)} \\
\mathrm{AG}_{(4)} \cdots \mathrm{TGTT}_{(3)}\end{array}$ & 53 & $180-216$ & 2 & 0.167 & 0.356 \\
\hline Pca 7 & GF111974 & $\begin{array}{l}\text { F: AAGCGTGATTGCCCTTAAT } \\
\text { R: GCCGTATTTGAGAAATGCTT }\end{array}$ & $\mathrm{TG}_{(6)} \cdot \mathrm{AGTC}^{(4)} \mathrm{AA}_{(4)}$ & 57 & $186-220$ & 2 & 0.167 & 0.356 \\
\hline Pcas & GF111975 & $\begin{array}{l}\text { F: ACCTGACGCCACTACTCCTC } \\
\text { R: TCACTTTGAATGCGAACCA }\end{array}$ & $\mathrm{CAT}_{(5)}$ & 53 & $207-210$ & 2 & 0.167 & 0.356 \\
\hline Pcalo & GF111976 & $\begin{array}{l}\text { F: TCAAGATGAACTGGAGGAAACA } \\
\text { R: CGCTAACGCCAACTATGCTA }\end{array}$ & $\mathrm{TCA}_{(4)}$ & 63 & $215-218$ & 1 & 0.000 & 0.000 \\
\hline
\end{tabular}

$\mathrm{F}=$ forward $; \mathrm{R}=$ reverse; $\mathrm{Ta}=$ optimal annealing temperature; $N_{\mathrm{A}}=$ number of alleles; $H_{\mathrm{O}}=$ observed heterozygosity; $H_{\mathrm{E}}=$ expected heterozygosity. All values are based on 10 accessions deposited at the active germplasm bank of Universidade Federal de Sergipe. 
the low number of evaluated individuals. However, results were obtained from a germplasm collection, which may not be in HWE. Indeed, there is absolutely no reason to expect HWE in germplasm collections since genotypes are collected in different populations and since no further breeding occurred from the moment of sampling; HWE is expected in panmictic populations. The presence of a large number of homozygotes can also be explained by the fact that patchouli is reproduced through stem cuttings.

The production of a patchouli genomic library enabled the development of 12 microsatellite primers, 6 of which were polymorphic in the evaluated genotypes. The development of these novel primers for patchouli will facilitate research on the conservation and diversity of the germplasm. The developed markers will also be essential for ongoing studies on the variability of the bank and other populations of this important aromatic species.

\section{ACKNOWLEDGMENTS}

Research supported by FAPITEC/SE, CAPES, and CNPq.

\section{Supplementary material}

\section{REFERENCES}

Billotte N, Lagoda PJL, Risterucci AM and Baurens FC (1999). Microsatellite-enriched libraries: applied methodology for the development of SSR markers in tropical crops. Fruits 54: 277-288.

Blank AF, Sant'Ana TCP, Santos PS, Arrigoni-Blank MF, et al. (2011). Chemical characterization of the essential oil from patchouli accessions harvested over four seasons. Ind. Crops Prod. 34: 831-837.

Creste S, Tulmann Neto A and Figueira A (2001). Detection of single sequence repeat polymorphisms in denaturing polyacrylamide sequencing gels by silver staining. Plant Mol. Biol. Rep. 19: 299-306.

Doyle JJ and Doyle JL (1990). Isolation of plant DNA from fresh tissue. Focus 12: 13-15.

Paul A, Thapa G, Basu A, Mazumdar P, et al. (2010). Rapid plant regeneration, analysis of genetic fidelity and essential aromatic oil content of micropropagated plants of Patchouli, Pogostemon cablin (Blanco) Benth. - An industrially important aromatic plant. Ind. Crops Prod. 32: 366-374.

Remya KS, Joseph S, Lakshmi PK and Akhila S (2010). Microsatellites in varied arenas of research. J. Pharm. Bioallied Sci. 2: 141-143.

Swamy MK, Balasubramanya S and Anuradha M (2010). In vitro multiplication of Pogostemon cablin Benth. through direct regeneration. Afr. J. Biotechnol. 9: 2069-2075.

Zucchi MI, Brondani RPV, Pinheiro JB, Chaves LJ, et al. (2003). Genetic structure and gene flow in Eugenia dysenterica DC in the Brazilian Cerrado utilizing SSR markers. Genet. Mol. Biol. 26: 449-457. 